\title{
Avaliação funcional de monócitos de bovinos naturalmente infectados pelo vírus da leucose bovina
}

[Functional evaluation of monocytes in cattle naturally infected with the bovine leucosis virus]

\author{
M.R. Azedo, M.G. Blagitz, F.N. Souza, F.J. Benesi, A.M.M.P. Della Libera \\ Departamento de Clínica Médica, Faculdade de Medicina Veterinária e Zootecnia, Universidade de São Paulo \\ Av. Prof. Dr. Orlando Marques de Paiva, 87 - Cidade Universitária \\ 05508-270 - São Paulo, SP
}

\begin{abstract}
RESUMO
Para a avaliação funcional de monócitos de bovinos infectados pelo vírus da leucose enzoótica bovina (LEB), foram coletadas amostras de sangue de 10 vacas com sorodiagnóstico negativo (SN), 10 com sorodiagnóstico positivo e que manifestavam linfocitose persistente (LP), e 10 com sorodiagnóstico positivo alinfocitóticas (AL). Os monócitos foram separados por gradiente de densidade e aderência em placa, submetidos aos testes de viabilidade por exclusão do azul de tripan, fagocitose de partículas de Zymosan, espraiamento em lamínula de vidro e quantificação da liberação de peróxido de hidrogênio $\left(\mathrm{H}_{2} \mathrm{O}_{2}\right)$ e de óxido nítrico (ON). Monócitos de animais com LP apresentaram os menores índices de viabilidade $(\mathrm{P}<0,001)$, de fagocitose $(\mathrm{P}<0,001)$ e de espraiamento $(\mathrm{P}=0,006)$. Também apresentaram maior produção de $\mathrm{H}_{2} \mathrm{O}_{2}$ sem prévio estímulo $(\mathrm{P}=0,001)$ e após estímulo in vitro com 12-miristato 13acetato de forbol $(\mathrm{P}=0,006)$ do que monócitos de animais $\mathrm{SN}$ e AL. $\mathrm{O}$ aumento da produção de $\mathrm{H}_{2} \mathrm{O}_{2}$ proporcionado pelo estímulo foi menor $(\mathrm{P}=0,015)$ nos monócitos de fêmeas que manifestaram LP. Não houve diferença na produção de ON pelos monócitos segundo os grupos. Os resultados indicam que o vírus da LEB, apesar de infectar linfócitos B, altera funcionalmente os monócitos circulantes em bovinos que manifestam LP.
\end{abstract}

Palavras-chave: bovino, fagocitose, radical livre, leucose enzoótica bovina

\begin{abstract}
Assuming that the bovine leukosis virus (BLV) alters quantitatively and qualitatively bovine circulating leukocyte subpopulations, thus influencing the innate immune response, monocytes function in BLVinfected cattle was assessed. Peripheral blood was obtained from 10 BLV-negative cows (SN), 10 naturally BLV-infected, non-lymphocytotic cows (AL), and $10 \mathrm{BLV}$-infected cows with persistent lymphocytosis $(P L)$. Monocytes were isolated by density gradient and adherence to plates. Cells were submitted to Trypan Blue dye exclusion viability assay, phagocytosis of Zymosan and cell-spreading assays, and quantification of hydrogen peroxide $\left(\mathrm{H}_{2} \mathrm{O}_{2}\right)$ and nitric oxide (NO) production. Monocytes from cattle with $P L$ had the lowest viability $(P<0.001)$, phagocytosis of Zymosan particles $(P<0.001)$, and spreading $(P=0.006)$ rates. Additionally, monocytes from cows with $P L$ had the highest production of $\mathrm{H}_{2} \mathrm{O}_{2}$, with no prior stimulus $(\mathrm{P}=0.001)$, and after in vitro stimulus with phorbol 12-myristate 13-acetate $(\mathrm{P}=0.006)$. Nonetheless, the boost in $\mathrm{H}_{2} \mathrm{O}_{2}$ production, provided by in vitro stimulus, observed in monocytes from cows with $P L$ was lower $(P=0.015)$ than that observed in monocytes from $S N$ and $A L$ cattle. There was no difference in NO production among groups. Results show that BLV, despite infecting $B$ lymphocytes, alters innate immune functions of monocytes isolated from BLV-infected cows expressing $P L$.
\end{abstract}

Keywords: cattle, phagocytosis, free radical, enzootic bovine leukosis

Recebido em 16 de março de 2010

Aceito em 17 de maio de 2011

E-mail: mr.azedo@usp.br

Apoio: FAPESP (Processo n ${ }^{\circ}$ 06/54500-0) 


\section{INTRODUÇÃO}

O vírus da leucose bovina (VLB) é um retrovírus oncogênico exógeno, que causa a leucose enzoótica bovina (LEB) (Schwartz e Levy, 1994), pertencente ao mesmo grupo dos vírus linfotrópicos de células $\mathrm{T}$ de primatas - vírus linfotrópicos de células T de humanos (HTLV) tipos 1,2 e 3 - e dos vírus linfotrópicos de células $\mathrm{T}$ de símios (Fauquet et al., 2004). De ocorrência universal, o VLB tem significativa incidência em praticamente todos os estados do Brasil (D'angelino et al., 1998a). O principal modo de transmissão do agente ocorre por meio de linfócitos infectados, podendo acontecer de forma horizontal ou vertical (Hopkins e Digiacomo, 1997). Na pecuária bovina, sua difusão ocorre, sobretudo, por meio de transferência iatrogênica de linfócitos infectados pelo uso indiscriminado de instrumentos sem a devida desinfecção. Desse modo, é relatada maior incidência em rebanhos leiteiros, posto que estes são submetidos a manipulações mais frequentes e intensas (Lorenz e Straub, 1987).

O VLB infecta principalmente linfócitos B (Schwartz et al., 1994), integrando seu genoma em regiões dispersas do genoma da célula hospedeira (Murakami et al., 2011b). Infectado, o animal pode apresentar-se com sorodiagnóstico positivo, sem a presença de linfocitose persistente (LP), ou com sorodiagnóstico positivo apresentando LP, caracterizado por uma elevação crônica no número de linfócitos B circulantes, encontrado em cerca de $30 \%$ dos bovinos infectados (Parodi, 1987) e considerado, por diversos autores, como uma manifestação benigna da enfermidade (Murakami et al., 2011a). Cerca de 0,1 a $10 \%$ dos animais infectados podem, ainda, desenvolver linfomas, caracterizados por infiltração mononuclear em órgãos ricos em tecido retículo-histiocitário, comumente os linfonodos, o baço, o coração, o útero, o abomaso, o fígado e/ou os rins, tendo previamente apresentado ou não LP (Cockerell e Reyes, 2000).

De fato, os sintomas são evidentes nos animais que desenvolvem a forma tumoral, quando os linfomas invadem os diferentes tecidos, e são dependentes do órgão envolvido (Schwartz e Levy, 1994). As perdas econômicas decorrentes dessa infecção, comumente relatadas, são devido à redução da produção de leite e do ganho de peso, à condenação de carcaças, aos custos com a reposição e ao aumento dos custos com serviços veterinários, apenas na pequena proporção de bovinos que apresentam linfomas (D'angelino et al., 1998b). Perdas indiretas também são verificadas e são decorrentes da restrição no comércio de animais ou de seus produtos (Tiwari et al., 2007).

Para melhor controle da doença, é necessário entender sua epidemiologia e patogenia. Por compartilhar arranjo estrutural e genético com os HTLVs, associados à leucemia de células $\mathrm{T}$ e linfoma em adultos (Sagata et al., 1985), e posto que tanto o VLB quanto o HTLV estão associados a doenças crônicas, com alterações quantitativas das células-alvo, e ao desenvolvimento tumoral, o VLB tem sido sugerido como um profícuo modelo animal para o estudo da interação entre vírus oncogênicos linfotrópicos e células do sistema imunitário (Hein e Griebel, 2003). Ainda que as principais células infectadas pelo HTLV sejam os linfócitos T (Yasunaga e Matsuoka, 2007), supõe-se que a patogenia envolve elementos imunomoduladores semelhantes em ambas as infecções (Gillet et al., 2007). Não obstante, a exata patogenia das infecções causadas pelos deltaretrovírus ainda não foi completamente esclarecida. O efeito dessas infecções, bem como sua ação sobre os mediadores imunitários, na função das diferentes populações de leucócitos, assim como no possível papel no desencadeamento de doenças oportunistas, também não está claro.

A proteção provida pelo sistema imunitário depende de uma intrincada interação e de uma complexa interdependência entre as células que o compõem. Assim, embora o VLB infecte principalmente linfócitos B, induzindo alterações quantitativas na subpopulação, a pouco elucidada sequência de eventos que leva ao desenvolvimento da LP pode provocar alterações na função das demais populações leucocitárias. Além disso, células da linhagem monócitomacrófago podem apresentar um papel importante como reservatórios para o vírus, como o fazem em outras infecções por retrovírus (Wyatt et al., 1989), podendo, assim, contribuir para a evolução de tais enfermidades.

De fato, a possibilidade de que leucócitos dessa linhagem sejam susceptíveis à infecção pelo 
VLB vem sendo estudada (Heeney et al., 1992). Uma característica comum a estas populações celulares é sua habilidade em reconhecer e destruir antígenos estranhos ou células infectadas, sem a necessidade de ter havido um prévio encontro com tais antígenos. Para tanto, utilizam-se da fagocitose e de atividades dependentes de oxigênio, relacionadas à explosão respiratória, e não dependentes de oxigênio, funções fundamentais na destruição e eliminação do agente invasor (Alberts et al., 2002). Além disso, os fagócitos interagem com as demais células que compõem o sistema imunitário, mormente os linfócitos, agindo como células apresentadoras de antígenos e, desse modo, participando como deflagradoras e efetoras na resposta gerada.

Possíveis alterações, relacionadas à gênese da LP, nas funções inerentes às demais populações leucocitárias, podem levar o animal a um estado depletivo na proteção fornecida pelo aparato imunitário, apontando um quadro de imunossupressão e descaracterizando a LP como uma manifestação benigna da doença. Desse modo, este estudo teve como objetivo avaliar a atividade funcional de monócitos isolados do sangue periférico de fêmeas bovinas naturalmente infectadas pelo VLB e que manifestaram ou não LP.

\section{MATERIAL E MÉTODOS}

Foram submetidas à venopunção jugular, pelo sistema a vácuo, 138 fêmeas bovinas com idade acima de 24 meses, da raça Holandesa, provenientes de quatro rebanhos, localizados em diferentes regiões do estado de São Paulo. Os animais, em bom estado nutricional, não haviam sido submetidos a tratamento com glicocorticoides nos últimos 30 dias, assim como não se encontravam em fase puerperal. Foram alocados em três grupos, conforme os resultados de dois testes de imunodifusão radial dupla de Ouchterlony (Antígeno glicoproteico (gp 51) extraído do envelope do VLB. Laboratório Tecpar - PR; controle de qualidade: Ministério da Agricultura, Pecuária e Abastecimento) e de dois hemogramas com intervalo de 90 dias. No diagnóstico de LP, foram utilizados como referência para a contagem leucocitária os dados obtidos por Távora (1998), somando-se três desvios-padrão (DP) à contagem absoluta de linfócitos de cada animal avaliado. Um grupo foi composto de 10 animais com sorodiagnóstico negativo nos dois testes sorológicos ( $\mathrm{SN}$ ), um grupo constituiu-se de 10 animais com sorodiagnóstico positivo sem LP (AL) e um grupo foi composto de 10 animais com sorodiagnóstico positivo manifestando LP (LP).

Para a avaliação funcional dos monócitos do sangue periférico, de cada animal foram coletadas, por venopunção jugular, amostras de $50 \mathrm{~mL}$ de sangue em tubos siliconizados com heparina, que foram identificados e encaminhados, sob refrigeração, ao laboratório de imunodiagnóstico.

Para o isolamento de monócitos, foi empregada a técnica utilizada por Werling et al. (1995), com modificações. Resumidamente, as amostras de sangue foram submetidas ao isolamento das células mononucleares por gradiente de densidade (Ficoll-Paque ${ }^{\mathrm{TM}}$ PLUS - GE Healthcare, Piscataway, NJ, USA; $n^{0}$ cat.: 171440-02). Alíquotas das suspensões celulares obtidas foram colocadas em quatro poços de placas de poliestireno com 24 poços. Estas permaneceram por 18 horas em estufa com 5\% de $\mathrm{CO}_{2}$, a $37^{\circ} \mathrm{C}$, para a maturação e aderência dos monócitos nas placas. Removidas da estufa, aos poços das placas foi gentilmente instilado tampão fosfato-salino (PBS) em temperatura ambiente, para a remoção de células que não estavam aderidas. Posteriormente, a placa permaneceu no gelo por cinco minutos e, após esse período, PBS a $4^{\circ} \mathrm{C}$ foi instilado para a remoção dos monócitos aderidos aos poços. As suspensões de monócitos foram, então, submetidas ao teste de viabilidade por exclusão do azul de tripan, e os monócitos foram identificados pela incorporação do corante vermelho neutro a $0,02 \%$. A concentração celular das suspensões foi, assim, ajustada, em meio RPMI (RPMI Medium 1640 - Gibco ${ }^{\circledR}$, Grand Island, NY, USA, $\mathrm{n}^{\circ}$ cat.: 11835-055), para atingir a concentração final de $2 \times 10^{6}$ monócitos viáveis/mL.

Dentro dos poços de novas placas de poliestireno, com 24 poços, foram colocadas lamínulas de vidro e, sobre estas, alíquotas de $200 \mu \mathrm{L}\left(4 \times 10^{5}\right.$ células $)$ da suspensão de monócitos. Nestas placas, cada coluna de quatro poços correspondia às células obtidas de um mesmo animal. Aos poços das duas linhas inferiores da placa foi adicionado $1 \mu \mathrm{g}$ de parede 
de células mortas de Saccaromyces cerevisiae (zymosan A from Saccharomyces cerevisiae Sigma-Aldrich $^{\circledR}$, St. Louis, MO, USA, $\mathrm{n}^{\circ}$ cat.: Z4250), por poço. Em seguida, as placas foram novamente incubadas em estufa com $5 \%$ de $\mathrm{CO}_{2}$, a $37^{\circ} \mathrm{C}$, durante duas horas, e, então, as células foram fixadas com a adição de glutaraldeído a 0,5\%. Para a quantificação da porcentagem de células espraiadas e de células que fagocitaram as partículas de Zymosan, a leitura das lamínulas, em duplicata, foi realizada em microscopia de contraste de fase em aumento de $600 \mathrm{X}$. Os resultados foram expressos pela porcentagem média ( \pm desvio-padrão) de células viáveis, de células espraiadas - observadas nas lamínulas em que não foram adicionadas partículas de Zymosan - e de células realizando fagocitose - verificada nas lamínulas em que foram adicionadas partículas de Zymosan.

No sobrenadante da cultura de monócitos, foi quantificada a liberação de peróxido de hidrogênio $\left(\mathrm{H}_{2} \mathrm{O}_{2}\right)$, baseada na oxidação de fenol vermelho dependente de peroxidase, realizada segundo o método colorimétrico descrito por Pick e Keisari (1980), adaptado para microensaio por Pick e Mizel (1981), e modificado por Russo et al. (1989), com e sem estímulo in vitro pela adição de 12-miristato 13-acetato de forbol (PMA). Também no sobrenadante da cultura de monócitos, a síntese de óxido nítrico $(\mathrm{ON})$ foi avaliada pela quantificação do acúmulo de nitrito, utilizando-se a reação de Griess, segundo técnica empregada por Adler et al. (1995). Os resultados foram expressos pela mediana e amplitude (em nmol/mL) da produção dessas espécies reativas de oxigênio (EROs) e de nitrogênio (ERNs) quantificada.

Foram verificadas a normalidade da distribuição dos resultados, utilizando-se 0 teste de Anderson-Darling, e sua homoscedasticidade, utilizando-se o teste $\mathrm{F}$ - para dados com distribuição normal - ou do teste de Lavene para dados que não apresentaram distribuição normal. Para a análise das frequências observadas, foi utilizado o teste do qui-quadrado. Para dados com distribuição normal, utilizaramse a análise de variância e o teste Tukey-Kramer para comparação de médias. Para a avaliação das diferenças entre medianas para dados que não apresentaram distribuição normal, usou-se o teste Kruskal-Wallis. Considerou-se significativo sempre que $\mathrm{P} \leq 0,05$.

\section{RESULTADOS}

Das 138 fêmeas submetidas à triagem, 75 (54,4\%) foram diagnosticadas como positivas para LEB. Dentre os animais positivos, 52 (82,5\%) não apresentaram, e 11 (17,5\%) manifestaram LP.

Os índices de viabilidade, segundo os grupos, são apresentados na Fig. 1. Os monócitos obtidos de animais que manifestaram LP mostraram menor índice de viabilidade $(\mathrm{P}<0,001)$ do que os obtidos de animais pertencentes aos grupos $\mathrm{SN}$ e AL.

Os índices de fagocitose, segundo os grupos, são apresentados na Fig. 2. Os monócitos de fêmeas pertencentes ao grupo LP manifestaram menor índice de fagocitose $(\mathrm{P}<0,001)$ do que os obtidos de animais dos grupos SN e AL.

Os índices de espraiamento, segundo os grupos, estão apresentados na Fig. 2. Os monócitos obtidos de fêmeas do grupo LP manifestaram menor índice de espraiamento $(\mathrm{P}=0,006)$ do que os monócitos de animais dos grupos SN e AL.

Os resultados da produção de $\mathrm{H}_{2} \mathrm{O}_{2}$, sem estímulo in vitro e após a adição de PMA, segundo os grupos, estão apresentados na Tab. 1. Os monócitos obtidos de fêmeas do grupo LP mostraram maior produção de $\mathrm{H}_{2} \mathrm{O}_{2}$, com $(\mathrm{P}=0,006)$ e sem $(\mathrm{P}=0,001)$ prévio estímulo, do que os monócitos obtidos de animais dos grupos $\mathrm{SN}$ e AL. Foi verificado que os monócitos obtidos de fêmeas do grupo LP responderam menos $(\mathrm{P}=0,015)$ ao estímulo in vitro do que os monócitos obtidos de animais pertencentes aos demais grupos experimentais.

Os resultados da produção de ON pelos monócitos, segundo os grupos, estão apresentados na Tab. 1. Não foi verificada diferença na produção de ON entre os grupos. 


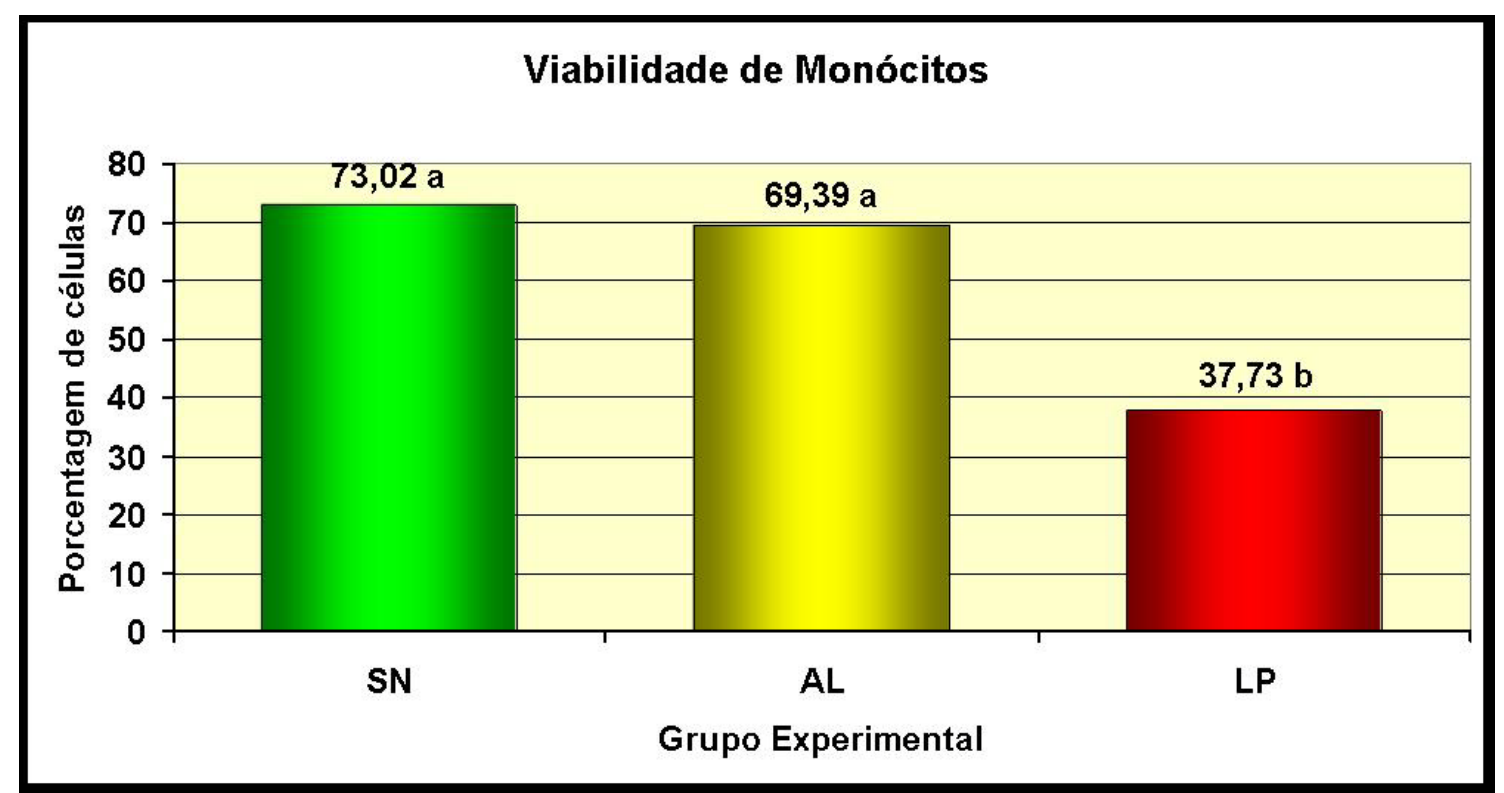

Figura 1. Média dos índices de viabilidade (porcentagens de células viáveis) observados em monócitos isolados do sangue periférico de fêmeas bovinas, estratificadas segundo o grupo experimental. Grupo SN: 10 vacas soronegativas para leucose enzoótica bovina (LEB); Grupo AL: 10 vacas soropositivas para LEB, alinfocitóticas; Grupo LP: 10 vacas soropositivas para LEB, apresentando linfocitose persistente. Resultados com letras distintas indicam diferença com $\mathrm{P}<0,001$ pelo teste $\mathrm{F}$.

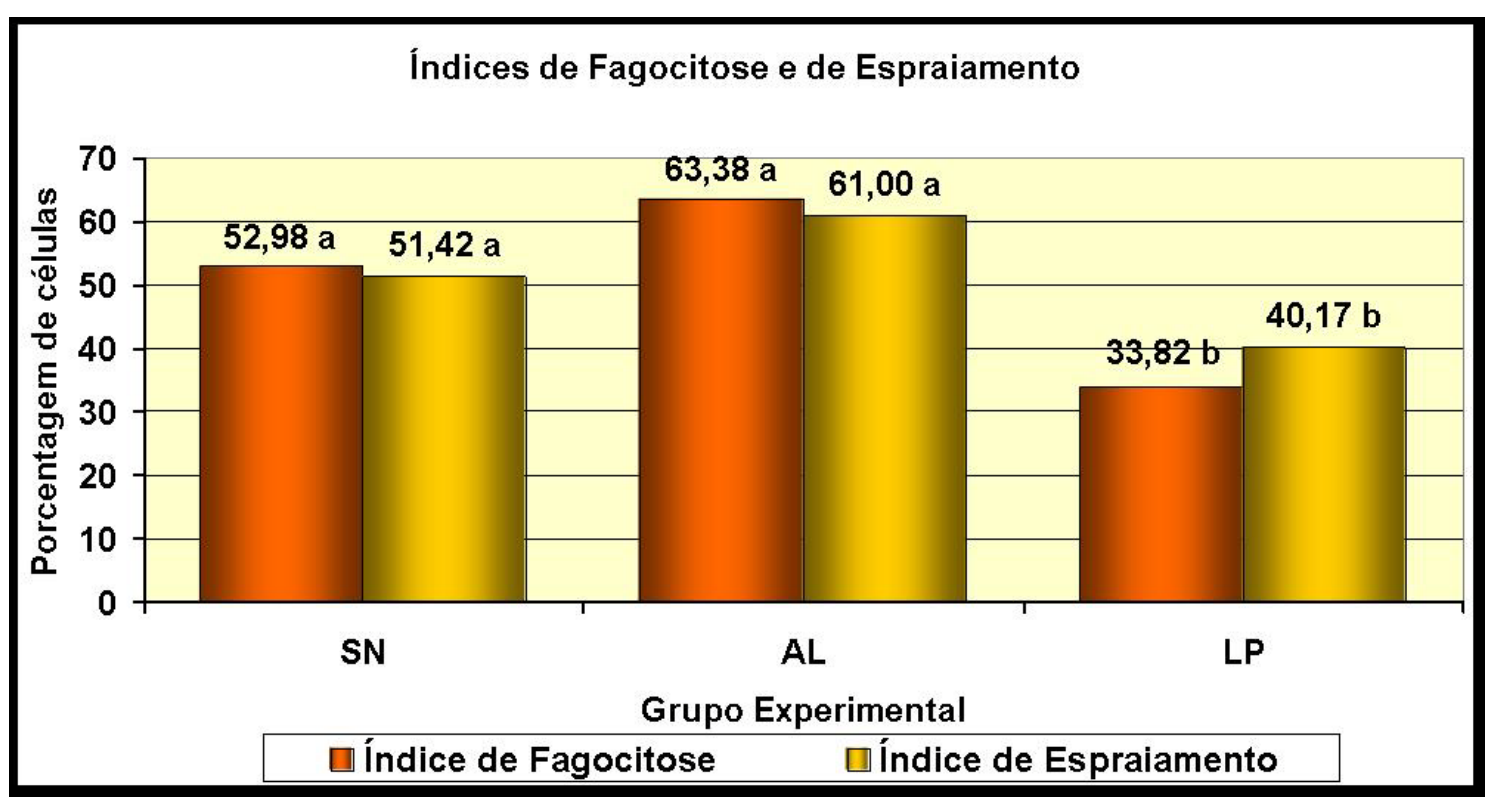

Figura 2. Média dos índices de fagocitose de partículas de Zymosan e de espraiamento (porcentagens de células) observados em monócitos isolados do sangue periférico de fêmeas bovinas, estratificadas segundo o grupo experimental. Grupo SN: vacas soronegativas para leucose enzoótica bovina (LEB); Grupo AL: vacas soropositivas para LEB, alinfocitóticas; Grupo LP: vacas soropositivas para LEB, apresentando linfocitose persistente. Resultados com letras distintas indicam diferença com $\mathrm{P}<0,001$ pelo teste $\mathrm{F}$. 
Tabela 1. Mediana e amplitude da produção de peróxido de hidrogênio $\left(\mathrm{H}_{2} \mathrm{O}_{2}\right)$ e de óxido nítrico (ON) $(\mathrm{nmol} / \mathrm{mL})$ por monócitos isolados de fêmeas bovinas, estratificadas segundo o grupo experimental

\begin{tabular}{lccc} 
& Grupo SN & Grupo AL & Grupo LP \\
\hline Produção de $\mathrm{H}_{2} \mathrm{O}_{2}$ sem estímulo & $6,74 \mathrm{a}$ & $9,49 \mathrm{a}$ & $28,98 \mathrm{~b}$ \\
& $(4,05-11,23)$ & $(4,31-11,17)$ & $(6,30-42,19)$ \\
Produção de $\mathrm{H}_{2} \mathrm{O}_{2}$ com PMA & $11,91 \mathrm{a}$ & $13,31 \mathrm{a}$ & $37,95 \mathrm{~b}$ \\
& $(8,39-19,02)$ & $(6,75-19,02)$ & $(7,28-52,60)$ \\
Incremento na produção de $\mathrm{H}_{2} \mathrm{O}_{2}$ & $65,10 \% \mathrm{a}$ & $45,10 \% \mathrm{a}$ & $24,04 \% \mathrm{~b}$ \\
& $(33,10-214,60)$ & $(5,90-241,30)$ & $(-18,86-56,68)$ \\
Produção de $\mathrm{ON}$ & $50,37 \mathrm{a}$ & $42,76 \mathrm{a}$ & $49,30 \mathrm{a}$ \\
& $(35,47-80,33)$ & $(36,02-60,11)$ & $(32,58-76,47)$ \\
\hline
\end{tabular}

Grupo SN: 10 vacas soronegativas para leucose enzoótica bovina (LEB); Grupo AL: 10 vacas soropositivas para LEB, alinfocitóticas; Grupo PL: 10 vacas soropositivas para LEB, apresentando linfocitose persistente. PMA: 12miristato 13-acetato de forbol. Resultados com letras distintas em uma mesma linha indicam diferença com $\mathrm{P}=0,001$ (produção de $\mathrm{H}_{2} \mathrm{O}_{2}$ sem estímulo), $\mathrm{P}=0,006$ (produção de $\mathrm{H}_{2} \mathrm{O}_{2}$ com adição in vitro de $\mathrm{PMA}$ ) e $\mathrm{P}=0,015$ (incremento na produção de $\mathrm{H}_{2} \mathrm{O}_{2}$ ), pelo teste Kruskal-Wallis.

\section{DISCUSSÃO}

Há evidências de que o vírus da LEB, que infecta principalmente linfócitos B (Schwartz et al., 1994), tenha, também, tropismo por outras células que fazem parte da resposta imunitária inata, nomeadamente aquelas da linhagem monócito/macrófago. Heeney et al. (1992) relataram que monócitos purificados por aderência continham o provírus em bovinos infectados naturalmente. Do mesmo modo, Mirsky et al. (1996) encontraram monócitos infectados, mas, utilizando citometria de fluxo, não puderam afirmar que não se tratava de contaminação por linfócitos B infectados, visto que as porcentagens celulares foram semelhantes.

Não foram encontrados relatos acerca da viabilidade de leucócitos em animais infectados pelo VLB. Apesar de Yang et al. (2004), ao investigarem células humanas infectadas pelo vírus da encefalite japonesa, terem observado que a replicação viral em monócitos não interferia em sua viabilidade, suspeita-se, atualmente, que a eliminação de células infectadas pelo VLB, apresentando vírus ativo e expressando proteínas virais em sua superfície, seja primordial para a evolução da enfermidade (Florins et al., 2008). Desta forma, isso pode explicar a menor viabilidade dos monócitos observada no presente estudo. De fato, Domenech et al. (2000), ao infectarem macrófagos bovinos in vitro, observaram que, embora apresentassem poucas alterações estruturais, tais células expressavam diversas proteínas virais, indicando replicação viral.
A capacidade funcional de células envolvidas na imunidade inata pode ser avaliada in vitro, direta ou indiretamente (Birmingham e Jeska, 1980). Mensura-se a competência dos fagócitos para englobar e lisar partículas ou microrganismos e quantifica-se a geração de diversas EROs e ERNs, ou, até mesmo, avalia-se aquilo que pode ser considerado como tentativa frustrada de fagocitose, manifestada pela aderência e espraiamento de macrófagos em lamínula de vidro (Stabel et al., 1997). Baseado na hipótese de que a infecção pode alterar a função das células da linhagem monócito-macrófago, este estudo avaliou a atividade de monócitos obtidos de fêmeas bovinas infectadas pelo VLB, utilizando provas de fagocitose de parede de células mortas de Saccaromyces cerevisiae, de espraiamento e de liberação de $\mathrm{H}_{2} \mathrm{O}_{2}$ e de $\mathrm{ON}$. Para tal, monócitos foram coletados de animais em bom estado nutricional, sem prévio tratamento com glicocorticoides e que não se encontravam em fase puerperal, fatores que poderiam influenciar sua resposta imunitária.

Segundo Werling et al. (1998), em células da linhagem monócito-macrófago infectadas pelo VLB, ocorre menor expressão dos receptores de membrana Fc $\gamma$, relacionadosà fagocitose. De fato, neste estudo, foi observado que células da linhagem monócito-macrófago isoladas de bovinos infectados apresentaram reduzido índice de fagocitose, quando comparado com os índices de animais não infectados pelo VLB. Altreuther et al. (2001), ao promoverem infeção in vitro pelo VLB das células da linhagem monócitomacrófago, verificaram que a função fagocítica não se alterava. Kaczmarczyk et al. (2005) 
também não observaram diferenças nos índices de fagocitose em leucócitos totais coletados de animais soropositivos e soronegativos para a LEB. Contudo, em todos esses estudos, não foram diferenciados animais que manifestassem LP. Azedo et al. (2008), ao avaliarem a fagocitose por meio da citometria de fluxo, constataram menor porcentagem de leucócitos totais realizando fagocitose entre as células obtidas de animais soropositivos com LP do que em células obtidas de animais soronegativos e soropositivos sem LP, resultados confirmados no presente estudo.

Diferentemente de estudos anteriores, o presente estudo avaliou especificamente a função fagocítica de monócitos isolados de animais infectados pelo VLB e que manifestavam LP. Estes animais apresentaram menor índice de fagocitose de partículas de Zymosan em relação aos dos grupos SN e AL. A não diferença verificada no índice de espraiamento das células da linhagem monócito-macrófago, atividade que traduz a ativação das células fagocíticas, representando uma tentativa de fagocitose segundo Birmingham e Jeska (1980), sugere que apenas os monócitos de animais com LP, quer por ação viral direta na célula infectada, quer por alterações nos mediadores inflamatórios, apresentem menor expressão dos receptores de membrana relacionados à fagocitose.

Uma variedade de métodos para avaliação da produção de EROs e ERNs tem sido desenvolvida (Soh, 2006). Entre eles, destacamse os que quantificam produtos finais do metabolismo oxidativo, como o $\mathrm{H}_{2} \mathrm{O}_{2}$ (Pick e Mizel, 1981). Watson et al. (1995) já haviam observado que a adição de substâncias estimuladoras da atividade oxidativa proporciona avaliação mais acurada dessa atividade, sobretudo quando da utilização de pequena quantidade de células e/ou de células com baixo índice de produção. Neste estudo, a liberação de $\mathrm{H}_{2} \mathrm{O}_{2}$ foi avaliada sem e com prévio estímulo por meio da adição de PMA. Em ambas as situações, observou-se que as células da linhagem monócito-macrófago de animais soropositivos com LP apresentaram maior liberação de $\mathrm{H}_{2} \mathrm{O}_{2}$ do que as células provenientes de animais dos demais grupos. Todavia, verificou-se que as células obtidas de fêmeas com LP responderam menos ao estímulo in vitro do que aquelas provenientes de animais pertencentes aos grupos $\mathrm{SN}$ e AL.

Utilizando citometria de fluxo, Azedo (2007) avaliou a produção intracelular de $\mathrm{H}_{2} \mathrm{O}_{2}$ em animais com LEB, com e sem estímulo in vitro, mediante adição de PMA, e observou menor produção de $\mathrm{H}_{2} \mathrm{O}_{2}$ nas células dos animais soropositivos com LP. Estes resultados diferem do encontrado no presente estudo, porém deve-se considerar que o autor avaliou a $\mathrm{H}_{2} \mathrm{O}_{2}$ no meio intracelular e que a $\mathrm{H}_{2} \mathrm{O}_{2}$ quantificada neste experimento foi aquela liberada no meio extracelular. Naquele estudo, o autor também observou que o aumento da produção de $\mathrm{H}_{2} \mathrm{O}_{2}$ proporcionado pela adição de PMA ocorreu nas células dos animais pertencentes a todos os grupos experimentais. No entanto, semelhante aos resultados verificados no presente estudo, foi verificado menor aumento nas células provenientes de animais com LP. Outra prova eficiente na avaliação da função das células da linhagem monócito-macrófago é a avaliação da liberação de ON. No presente estudo, não foi verificada diferença em tal produção, quando comparados os diferentes grupos experimentais. Não foram encontrados estudos acerca da liberação de óxido nítrico produzido pelos leucócitos sanguíneos obtidos de bovinos infectados pelo VLB.

Estudos sugerem que uma alteração quantitativa e qualitativa no perfil de citocinas envolvidas na resposta imune celular (Th-1) para aquele encontrado na resposta humoral (Th-2) possa estar envolvida na progressão da enfermidade para LP ou linfoma (Kabeya et al., 2001). Após estimulo in vitro com a adição de lipopolissacarídeos de Escherichia coli (LPS), Werling et al. (1995) demonstraram que a infecção pelo VLB altera a produção e a atividade de citocinas em monócitos. Tais alterações no perfil de citocinas podem interferir na atividade das demais populações celulares relacionadas ao sistema imunológico e podem ser responsáveis pela alteração da atividade oxidativa e fagocítica de monócitos observada no presente estudo.

No entanto, enquanto ovinos experimentalmente infectados pelo VLB manifestam LP com aumento exponencial do número de linfócitos circulantes, chegando a atingir $800.000 / \mathrm{mm}^{3}$, bovinos naturalmente infectados e que 
apresentam LP mantêm uma quantidade elevada, porém constante, de linfócitos circulantes (Florins et al., 2008), sugerindo uma constante eliminação das células infectadas que expressam antígenos virais. Tal eliminação pode estar associada à atuação de linfócitos- $\gamma \delta$, induzidos pela ação do interferon- $\gamma$ (INF- $\gamma)$. Murakami et al. (2004), após inoculação intraperitoneal de IFN- $\gamma$, observaram aumento na quantidade de linfócitos- $\gamma \delta$ circulantes, diminução do número de linfócitos e supressão da replicação viral in vitro em células de bovinos infectados. Lundberg e Splitter (2000) haviam concluído que, em bovinos, linfócitos- $\gamma \delta$ reconhecem o anfgeno do VLB expresso em células infectadas. Por sua vez, em ovinos infectados, baixos níveis de expressão viral são detectados in vivo (Gillet et al., 2007).

Acredita-se que fatores virais, alterações genéticas e epigenéticas, assim como a resposta imunitária do hospedeiro, contribuam para a gênese tanto da LP, em animais infectados pelo $\mathrm{VLB}$, quanto da leucemia de células $\mathrm{T}$, em humanos infectados pelo HTLV (Merimi et al., 2009). A despeito de o presente estudo não ter verificado se os monócitos apresentavam-se infectados, os resultados sugerem que, em animais manifestando LP, tais células podem conter vírus ativos e que, por expressarem peptídeos virais, elas sofram processo de eliminação, justificando as alterações observadas.

\section{CONCLUSÕES}

Pelos métodos utilizados, conclui-se que bovinos naturalmente infectados pelo VLB, e que manifestam LP, apresentam alterações na atividade fagocítica e no metabolismo oxidativo de células da linhagem monócito-macrófago, demonstrando, assim, vulnerabilidade funcional.

\section{REFERÊNCIAS BIBLIOGRÁFICAS}

ADLER, H.; FRECH, B.; THÖNY, M. et al. Inducible nitric oxide synthase in cattle. Differential cytokine regulation of nitric oxide synthase in bovine and murine macrophages. $J$. Immunol., v.154, p.4710-4718, 1995.

ALBERTS, B.; JOHNSON, A.; LEWIS, J. et al. Molecular biology of the cell. 4. ed. New York: Garland, 2002. 1616p.
ALTREUTHER, G.; LLAMES, L.; NEUENSCHWANDER, S. et al. Morphologic and functional changes in bovine monocytes infected in vitro with the bovine leukaemia virus. Scand. J. Immunol., v.54, p.459-469, 2001.

AZEDO, M.R. Influência da leucose enzoótica bovina na atividade oxidativa de leucócitos. 2007. 151f. Dissertação (Mestrado em Clínica Veterinária) - Faculdade de Medicina Veterinária e Zootecnia, Universidade de São Paulo, São Paulo, SP.

AZEDO, M.R.; MASSOCO, C.O.; BLAGITZ, M.G. et al. Influence of enzootic bovine leukosis on phagocytic function of circulating leukocytes from animals with persistent lymphocytosis. Braz. J. Vet. Res. Anim. Sci., v.45, p.390-397, 2008.

BIRMINGHAM, J.R.; JESKA, E.L. The isolation, long-term cultivation and characterization of bovine peripheral blood monocytes. Immunology, v.41, p.807-814, 1980.

COCKERELL, G.L.; REYES, R.A. Bovine leukemia virus-associated lymphoproliferative disorders. In: FELDMAN, B.F.; ZINKL, J.G.; JAIN, N.C. (Eds.). Schalm's veterinary hematology. 5.ed, Philadelphia: Lippincott Williams \& Wilkins, 2000. p.614-619.

D'ANGELINO, J.L.; GARCIA, M.; BIRGEL, E.H. Epidemiological study of enzootic bovine leukosis in Brazil. Trop. Anim. Health Prod., v.30, p.13-15, 1998a.

D'ANGELINO, J.L.; GARCIA, M.; BIRGEL, E.H. Productive and reproductive performance in cattle infected with bovine leukosis virus. $J$. Dairy Res., v.65, p.693-695, 1998b.

DOMENECH, A.; GOYACHE, J.; LLAMES, L. et al. In vitro infection of cells of the monocytic/macrophage lineage with bovine leukaemia virus. J. Gen. Virol., v.81, p.109-118, 2000.

FAUQUET, C.M.; MAYO, M.A.; MANILOFF, J. et al. (Eds.). Virus Taxonomy: Report of the International Committee on Taxonomy of Viruses, 8., San Diego: Academic, 2004. 1162p.

FLORINS, A.; BOXUS, M.; VANDERMEERS, F. et al. Emphasis on cell turnover in two hosts infected by bovine leukemia virus: A rationale for host susceptibility to disease. Vet. Immunol. Immunopathol., v.125, p.1-7, 2008. 
GILLET, N.; FLORINS, A.; BOXUS, M. et al. Mechanisms of leukemogenesis induced by bovine leukemia virus: prospects for novel antiretroviral therapies in human. Retrovirology, v.4, p.18, 2007.

HEENEY, J.L.; VALLI, P.J.; JACOBS, R.M. et al. Evidence for bovine leukemia virus infection of peripheral blood monocytes and limited antigen expression in bovine lymphoid tissue. Lab. Invest., v.66, p.608-617, 1992.

HEIN, W.R.; GRIEBEL, P.J. A road less travelled: large animal models in immunological research. Nat. Rev. Immunol., v.3, p.79-84, 2003.

HOPKINS, S.G.; DIGIACOMO, R.F. Natural transmission of bovine leukemia virus in dairy and beef cattle. Vet. Clin. N.Am.: Food Anim. Pract., v.13, p.107-128, 1997.

KABEYA, H.; OHASHI, K.; ONUMA, M. Host immune responses in the course of bovine leukemia virus infection. J. Vet. Med. Sci., v.63, p.703-708, 2001.

KACZMARCZYK, E.; BOJAROJCNOSOWICZ, B.; FIEDOROWICZ, A. Leukocyte acid phosphatase and metabolic efficiency of phagocytes in the first lactation trimester of cows from a leukaemic herd. J. Appl. Genet., v.46, p.59-67, 2005.

LORENZ, R.J.; STRAUB, O.C. The epidemiology of enzootic bovine leukosis. In: BURNY, A.; MAMMERICKX, M. (Eds.). Enzootic bovine leukosis and bovine leukemia virus. Boston: Martinus Nijhoff, 1987. p.51-68.

LUNDBERG, P.; SPLITTER, G. A. gammadelta(+) T-Lymphocyte cytotoxicity against envelope-expressing target cells is unique to the alymphocytic state of bovine leukemia virus infection in the natural host. J. Virol., v.74, p.8299-8306, 2000.

MERIMI, M.; OZKAN, Y.; CLEUTER, Y. et al. Epigenetics and leukemia: unraveling oncogenic processes in the BLV ovine model. Front. Biosci., v.1, p.154-63, 2009.

MIRSKY, M.L.; OLMSTEAD, C.A.; DA, Y.; LEWIN, H.A. The prevalence of proviral bovine leukemia virus in peripheral blood mononuclear cells at two subclinical stages of infection. $J$. Virol., v.70, p.2178-2183, 1996.
MURAKAMI, H.; KUROIWA, T.; SUZUKI, K. et al. Analysis of syk expression in bovine lymphoma and persistent lymphocytosis induced by bovine leukemia virus. J. Vet. Med. Sci., v.73, p.41-45, 2011a.

MURAKAMI, H.; YAMADA, T.; SUZUKI, M. et al. Bovine leukemia virus integration site selection in cattle that develop leukemia. Virus Res., v.156, p.107-112, 2011b.

MURAKAMI, K.; SENTSUI, H.; INOSHIMA, $Y$. et al. Increase in gammadelta $\mathrm{T}$ cells in the blood of cattle persistently infected with bovine leukemia virus following administration of recombinant bovine IFN-gamma. Vet. Immunol. Immunopathol., v.101, p.61-71, 2004.

PARODI, A.L. Pathology of enzootic bovine leukosis: comparision with the sporadic form. In: BURNY, A.; MAMMERICKX, M. (Ed.). Enzootic bovine leukosis and bovine leukemia virus. Boston: Martinus Nijhoff, 1987. p.15-49.

PICK, E.; KEISARI, Y. A simple colorimetric method for the measurement of hydrogen peroxide produced by cells in culture. $J$. Immunol. Methods, v.38, p.161-170, 1980.

PICK, E.; MIZEL, D. Rapid microassays for measurement of superoxide and hydrogen peroxide production by macrophages in culture using an automatic enzyme immunoassay reader. J. Immunol. Methods, v.46, p.211-226, 1981.

RUSSO, M.; TEIXEIRA, H.C.; MARCONDES, M.C. et al. Superoxide-independent hydrogen peroxide release by activated macrophages. Braz. J. Med. Biol. Res., v.22, p.1271-1273, 1989.

SAGATA, N.; YASUNAGA, T.; TSUZUKUKAWAMURA, J. et al. Complete nucleotide sequence of the genome of bovine leukemia virus: its evolutionary relationship to other retroviruses. Proc. Natl. Acad. Sci. U S A, v.82, p.677-681, 1985.

SCHWARTZ, I.; BENSAID, A.; POLACK, B. et al. In vivo leukocyte tropism of bovine leukemia virus in sheep and cattle. J. Virol., v.68, p.45894596, 1994.

SCHWARTZ, I.; LEVY, D. Pathobiology of bovine leukemia virus. Vet. Res., v.25, p.521536, 1994. 
$\mathrm{SOH}, \mathrm{N}$. Recent advances in fluorescent probes for the detection of reactive oxygen species. Anal. Bioanal. Chem., v.386, p.532-543, 2006.

STABEL, J.R.; KEHRLI JR, M.; REINHARDT, T.A. et al. Functional assessment of bovine monocytes isolated from peripheral blood. Vet. Immunol. Immunopathol., v.58, p.147-153, 1997.

TAVORA, J.P.F. Hemograma de bovinos das raças Gir, Girolando e Holandesa criados no estado de São Paulo: estabelecimento dos valores de referência e avaliação das influências de fatores de variabilidade raciais, etários $e$ sexuais. 1998. 163f. Tese (Doutorado em Clínica Veterinária) - Faculdade de Medicina Veterinária e Zootecnia, Universidade de São Paulo, São Paulo, SP.

TIWARI, A.; VANLEEUWEN, J.A.; DOHOO, I.R. et al. Production effects of pathogens causing bovine leukosis, bovine viral diarrhea, paratuberculosis, and neosporosis. J. Dairy Sci., v.90, p.659-669, 2007.

WATSON, G.L.; SLOCOMBE, R.F.; ROBINSON, N.E. et al. Definition of chemiluminescence and superoxide production responses of bovine neutrophils to selected soluble and particulate stimulants, and comparisons with the responses to Pasteurella haemolytica. Am. J. Vet. Res., v.56, p.1045-1054, 1995.
WERLING, D.; HOWARD, C.J.; NIEDERER, E. et al. Analysis of the phenotype and phagocytic activity of monocytes/macrophages from cattle infected with the bovine leukaemia virus. Vet. Immunol. Immunopathol., v.62, p.185195, 1998.

WERLING, D.; SILEGHEM, M.; LUTZ, H. et al. Effect of bovine leukemia virus infection on bovine peripheral blood monocyte responsiveness to lipopolysaccharide stimulation in vitro. Vet. Immunol. Immunopathol., v.48, p.77-88, 1995.

WYATT, C.R.; WINGETT, D.; WHITE, J.S. et al. Persistent infection of rabbits with bovine leukemia virus associated with development of immune dysfunction. J. Virol., v.63, p.44984506, 1989.

YANG, K.D.; YEH, W.T.; CHEN, R.F. et al. A model to study neurotropism and persistency of Japanese encephalitis virus infection in human neuroblastoma cells and leukocytes. J. Gen. Virol., v.85, p.635-642, 2004.

YASUNAGA, J.; MATSUOKA, M. Human Tcell leukemia virus type I induces adult T-cell leukemia: from clinical aspects to molecular mechanisms. Cancer Control, v.14, p.133-140, 2007. 